\title{
Design and Development of a Tactile Wind Tunnel for Educational Purposes
}

Madison Bowersox, Creighton McIntyre, Prathmesh Anantwar, Kyle Clark, Abhee Singh, and Ruth May- Department of Mechanical and Aerospace Engineering

\section{Overview}

An academic partnership between the University of Alabama in Huntsville (UAH) and the Cape Peninsula University of Technology (CPUT) in South Africa, known as the ALLiance for International Excellence among the future Space workforce (ALLIES), was formed in 2012.

- This partnership has now extended to the Universidad Autonoma de Centro America (UACA) and Universidad Latina de Costa Rica (ULCR).

-ALLIES is intended to develop the future of the Science, Technology, Engineering, and Mathematics (STEM) and space workforce by focusing on the following goals:

- Establish collaborative efforts between universities in various nations.

- Provide undergraduate engineering students the opportunity to work on international engineering design

projects.

- Encourage Kindergarten through $12^{\text {th }}$ grade (K-12) students to pursue careers in STEM fields.

Objective

- To design a wind tunnel for classroom demonstration for K-12 students by the UAH American Society of Mechanical Engineers (ASME) student section and the North Alabama ASME professional section.

\section{Impact}

Ongoing senior design project effort - the 6th wind tunnel within this project series.

Knowledge and research utilized in the production of the wind tunnel will be used in K-12 STEM outreach in the North Alabama region as well as in Costa Rica. - Currently impacting primary, sec

- Will be used by the UAH ASME student section for STEM outreach purposes as well as the North Alabama Section of ASME.

- The wind tunnel provides a tactile problem based learning experience that will enable young students to intuitively understand numerous theoretical concepts including lift, force, airflow, velocity, and airfoils, to name a few.

- The UAH student design team has garnered extensive knowledge and experience utilizing the National Aeronautics and Space Administration (NASA) Systems Engineering Handbook in the design and development of a product.
Final Product Specifications

-Final Size: 32.53 inches long and 28 inches wide -Final Weight: $40 \mathrm{lb}$

-Maximum Air Speed in test Section : 17.4mph

- Lift Capacity: 0.04lb-0.11/b depending on the Angle of Attack

Construction Materials:

Acrylic

Plywood

•Functionality:

Demonstrate lift

Demonstrate change in Angle of Attack

FEA of Test Article and Test Section

For NACA 4412 airfoil at mph $20 \mathrm{mph}$ speed

and 10 degrees angles of attack

- Calculated lift force $=0.152 \mathrm{lbf}$

Maximum stress = 5.87E-5 psi

Maximum Deflection = 7.322E-6 in.

Test section stress analysis

Maximum stress $=6.48 \mathrm{E}-6 \mathrm{psi}$

Maximum Deflection = $2.84252 \mathrm{E}-4$ in."

Methodology

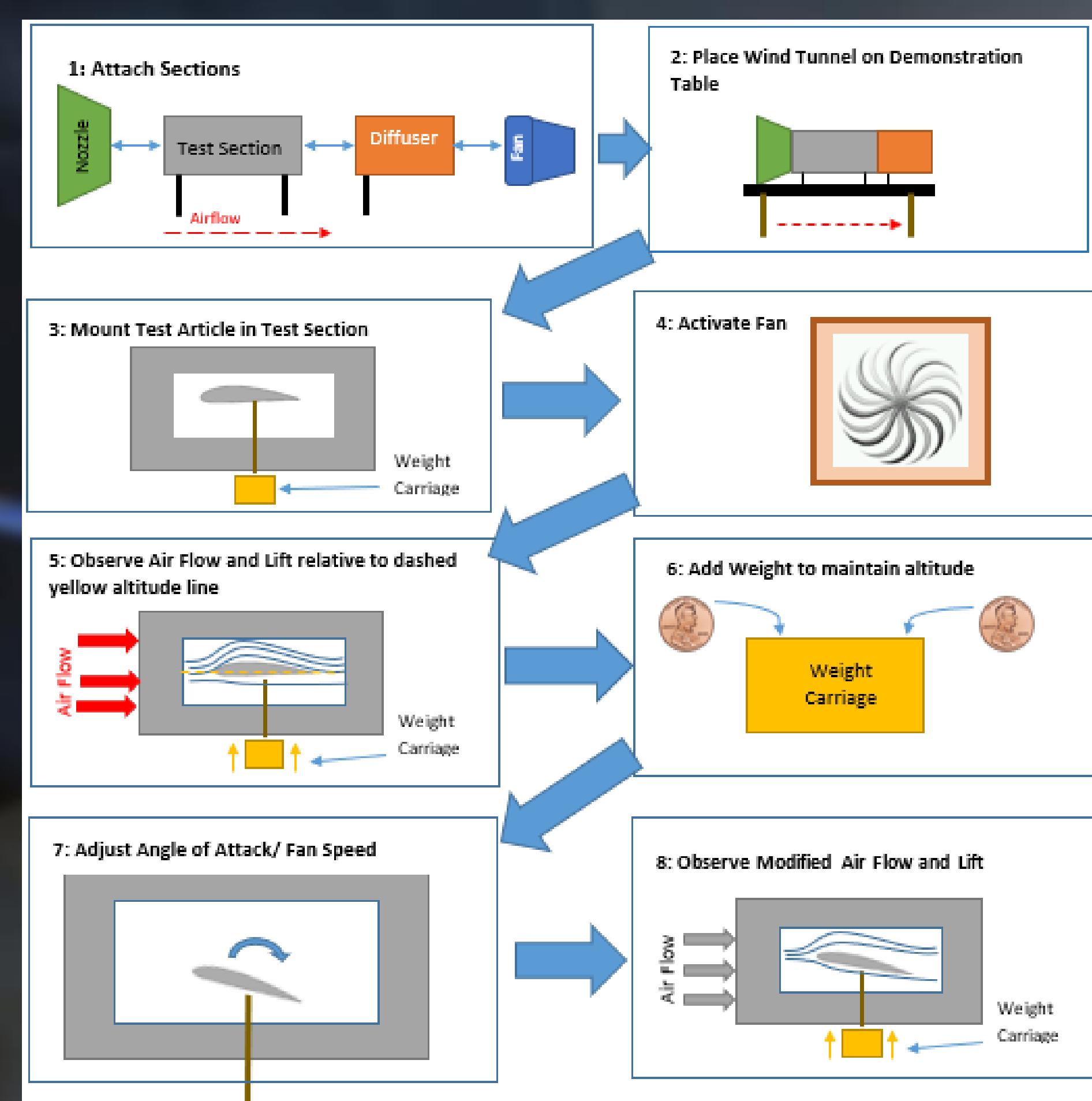

Concept of Operations

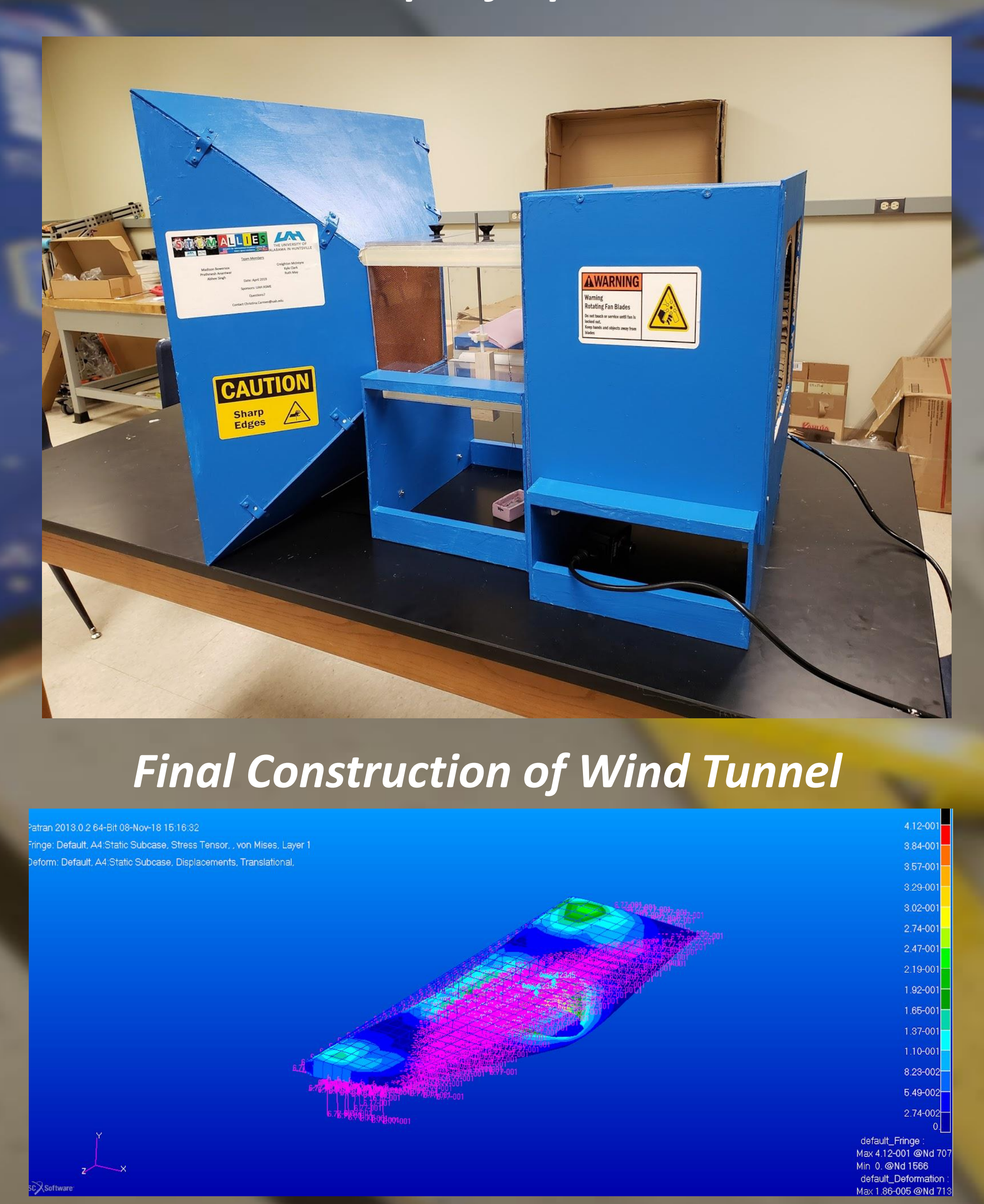

FEA of NACA 4412 Airfoil

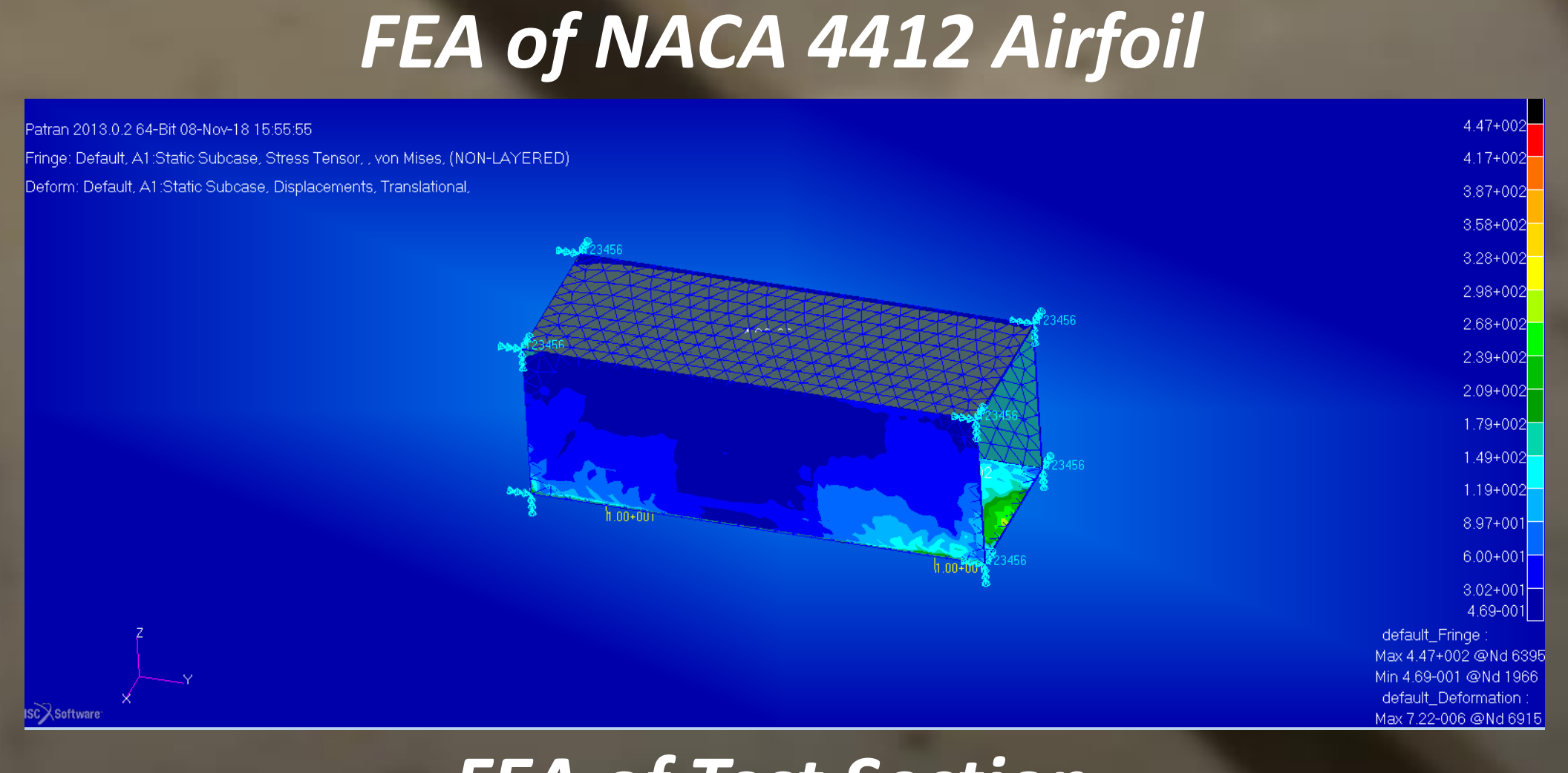

FA of Test Section

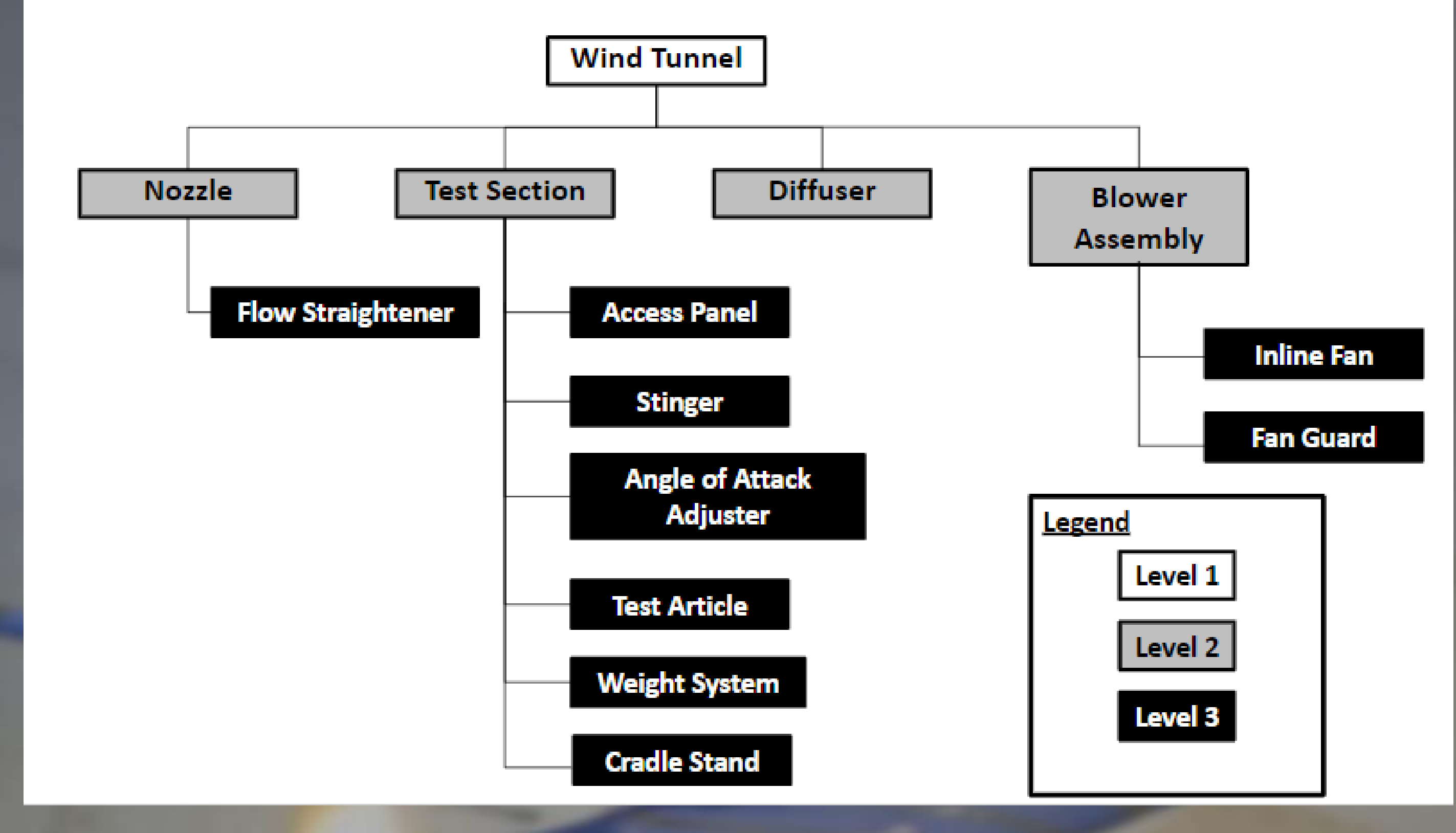

Product Breakdown Structure

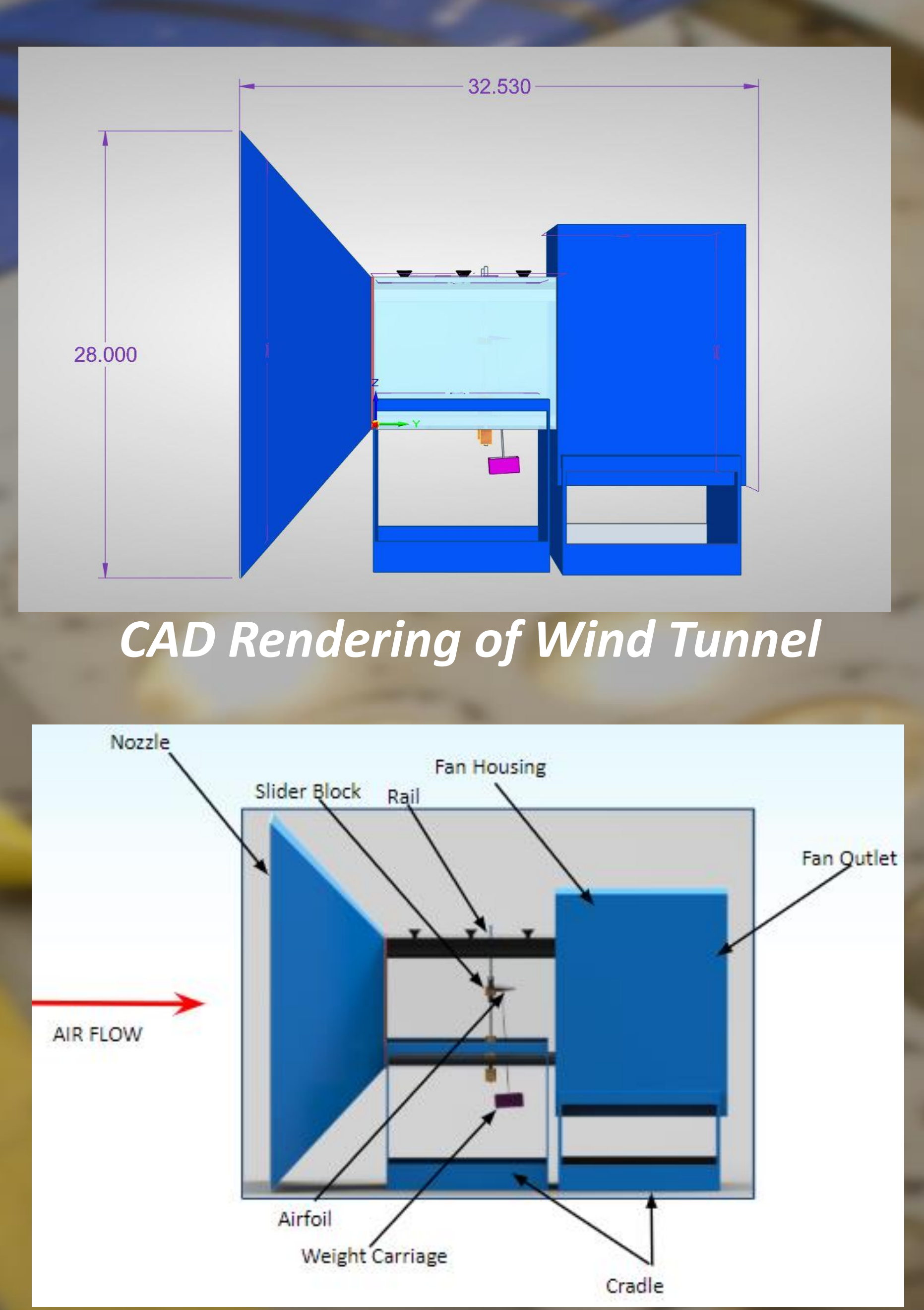

Details of Wind Tunnel
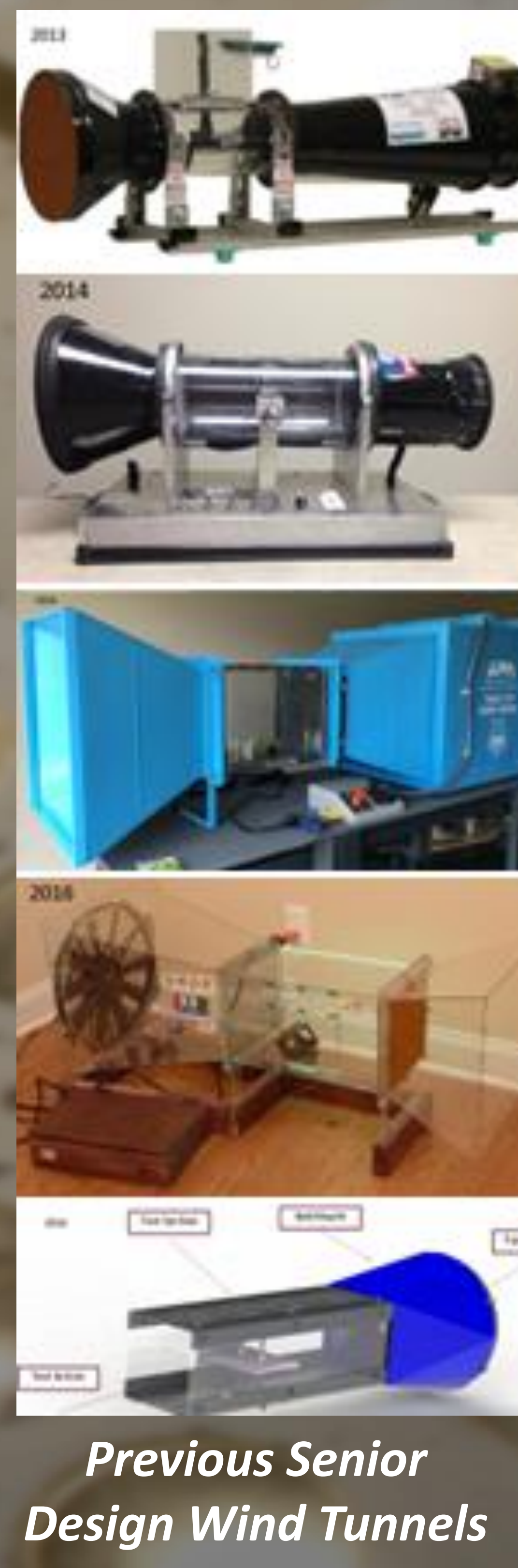

\section{Acknowledgements}

The Tabletop Wind Tunnel design team would like to thank Dr. Christina Carmen (The University of Alabama in Huntsville Team Advisor and Senior Design Instructor) and Mr. Herb Guendel (STEM Outreach Contact for International Collaboration) 